\title{
Uniform Convergence of Cosine Series With Coefficient from New Class of General Monotone
}

\section{Moch Aruman Imron}

Department of Mathematics, University of Brawijaya, Malang, Indonesia

\begin{abstract}
General monotone sequences class (GMS) has been introduced by Tikhonov. Then Bogdan Szal extended this class to the new class called new class of general monotone. By using non-negative sequence is called $\beta$ to controle the difference of sine series coefficient. By substituting $\beta$ of modulus of sine series coefficient, we study uniform convergence of new class of general monotone on cosine series.
\end{abstract}

Keyword: New Class General Monotone, Cosine Series, Uniform Convergence

Abstrak. Kelas general monotone sequences (GMS) telah diperkenalkan oleh Tikhonov. Lalu Bogdan Szal memperluas kelas ini ke kelas baru disebut new class of general monotone. Dengan menggunakan barisan non-negatif yang disebut $\beta$ untuk mengatur selisih dari koefisien deret sinus. Dengan mensubstitusi $\beta$ dari modulus koefisien deret sinus, kami pelajari konvergen seragam dari new class of general monotone pada deret kosinus.

Kata Kunci: New Class General Monotone, Deret Kosinus, Konvergen Seragam

Received 28 April 2019 | Revised 19 June 2019| Accepted 27 July 2019

\section{Introduction}

Chaundy and Jollife [6] have been discussed about the classic theorem, the necessary and sufficient condition of uniform convergence of

$$
\sum_{n=1}^{\infty} a_{n} \sin n x
$$

is $\lim _{n \rightarrow \infty} n a_{n}=0$, if $a=\left\{a_{i}\right\}$ is decreasing monotone and tending to zero. Tikhonov extended decreasing monotone (1) to General Monotone (GM) by Tikhonov [5].

Definition 1.1. Let $a=\left\{a_{i}\right\}$ be a complex sequence and let $\beta=\left\{\beta_{i}\right\}$ be a non-negative real sequence, i.e. $\beta_{i} \geq 0$ for each $i \in \mathbb{N}$. The ordered pair $(a, \beta)$ is in $\beta$ general monotone, if there exists positive constant $C$ and the following inequality stands for every $n \in \mathbb{N}$

*Corresponding author at: University of Brawijaya, Malang, Indonesia 


$$
\sum_{k=n}^{2 n-1}\left|a_{k}-a_{k+1}\right| \leq C \beta_{n}
$$

Bogdan Szal [1] extended class of general monotone called class $(\beta, r)$ general monotone.

Definition 1.2. If $a=\left\{a_{i}\right\}$ complex sequence numbers and $\beta=\left\{\beta_{i}\right\}, \beta_{i} \geq 0$ for each $i \in \mathbb{N}$. An ordered pair $(a, \beta)$ is element in the class of ordered pair $(\beta, r)$ of general monotone $(G M(\beta, r))$, if we can find some positive constant $C$ and the inequality

$$
\sum_{k=n}^{2 n-1}\left|a_{k}-a_{k+r}\right| \leq C \beta_{n}
$$

holds for each $n \in \mathbb{N}$ and $r \in \mathbb{N}$.

For

$$
\beta^{*}=\beta^{*}(r)=\sum_{k=n}^{n+r-1}\left|a_{k}\right|+\sum_{k=\left[\frac{n}{c}\right]}^{[c n]} \frac{\left|a_{k}\right|}{k}
$$

and some $c>1$ and it can be obtained some result at follows

Theorem 1.3. Let $a=\left\{a_{i}\right\}, a_{i} \geq 0$ for each $i \in \mathbb{N}$ and $\left(a, \beta^{*}\right) \in G M\left(\beta^{*}, r\right)$, where $r$ is natural numbers. If $r \geq 1$ and the sine series in point (1) is convergent uniformly to continuous function, then $\lim _{n \rightarrow \infty} n a_{n}=0$.

Theorem 1.4. Let $a=\left\{a_{i}\right\}, a_{i} \geq 0$ for each $i \in \mathbb{N}$ and $\left(a, \beta^{*}\right) \in G M\left(\beta^{*}, r\right), r \in \mathbb{N}$. If $r=2$ and $\lim _{n \rightarrow \infty} n\left|a_{n}\right|=0$, then the sine series in point (1) converges uniformly.

Throught this paper, by using a new class of the general monotone [1] and let $\beta_{n}=a_{n} \geq 0$, we discuss uniform convergence of this new class on cosine series like as [2], [3], [4].

\section{Materials and Methods}

This research is worked by study of literature and supporting paper from journals to get an understanding, then get results related to the research that published in the scientific journal. The results of this research are communicated in a journal. In summary the method of the research is discussing uniform convergence with coefficient belonging to the new class of the general monotone.

\section{Results and Discussion}

In this section, we will discuss some modification of new class general monotone by taking a non-negative real sequence for controlling the sum of difference sine series coefficient. Let the series 


$$
f(x)=\sum_{k=1}^{\infty} a_{k} \cos k x
$$

where $a=\left\{a_{k}\right\}$ is a real sequence that tends to zero, i.e., $a_{k} \rightarrow 0$ as $k \rightarrow \infty$. We define sums of series $f(x)$ where the point of the series converges.

Definition 3.1. A non-negative real sequence $a=\left\{a_{i}\right\}$ is called element of class of $G M\left(\mathbb{R}^{+}, 2\right)$ if we can find positive constant $C$, i.e. $C>0$ and the relation

$$
\sum_{k=n}^{2 n-1}\left|a_{k}-a_{k+2}\right| \leq C \boldsymbol{a}_{\boldsymbol{n}}
$$

holds for each $n \in \mathbb{N}$.

Lemma 3.2. If $\boldsymbol{a} \in G M\left(\mathbb{R}^{+}, 2\right)$ and $\left\{n a_{n}\right\}$ converges to 0 , then

$$
\lim _{n \rightarrow \infty} n \sum_{v=n}^{\infty}\left|a_{v}-a_{v+2}\right|=0
$$

Proof. Let $d_{n}=\sup _{v \geq n}\left(v a_{v}\right)$, then $d_{n}$ decreasing monotone and $\lim _{n \rightarrow \infty} d_{n}=\lim _{n \rightarrow \infty} m a_{m}=0$. For $a \in M\left(\mathbb{R}^{+}, 2\right)$, we have

$$
\begin{gathered}
n \sum_{v=n}^{\infty}\left|a_{v}-a_{v+2}\right|=n \sum_{s=0}^{\infty} \sum_{v=2^{s} n}^{2^{s+1} n-1}\left|a_{v}-a_{v+2}\right| \\
\leq \sum_{s=0}^{\infty} 2^{s} n \frac{a_{2^{s} n}}{2^{s}} \leq \sum_{s=0}^{\infty} \frac{n a_{n}}{2^{s}}=2 C^{\prime} n a_{n} .
\end{gathered}
$$

Thus

$$
\lim _{n \rightarrow \infty} n \sum_{v=n}^{\infty}\left|a_{v}-a_{v+2}\right|=0 .
$$

Theorem 3.3. Let $a \in G M\left(\mathbb{R}^{+}, 2\right)$ and $\lim _{n \rightarrow \infty} n a_{n}=0$, if $\sum_{k=1}^{\infty} a_{k}$ converges then cosine series (1) converges uniformly on closed interval $[0, \pi]$.

Proof. Since $\sum_{k=1}^{\infty} a_{k}$ converges and $\left\{a_{k}\right\}$ is a null and non negative sequence, then

$$
\lim _{n \rightarrow 0} \sum_{k=n}^{\infty} a_{k}=0
$$

Let us calculate $f(x)-S_{m}(f, x)$, where

$$
S_{m}(g, x)=\sum_{j=1}^{m} a_{j} \cos j x
$$

we get 


$$
\begin{aligned}
f(x)-S_{m-1}(f, x) & =\sum_{k=m}^{\infty} a_{j} \cos j x \\
& =\sum_{k=m}^{\infty} \Delta a_{k} D_{k}(x)-a_{m} D_{m-1}(x)=A+B
\end{aligned}
$$

where $D_{m}(x)=\sum_{j=1}^{m} \cos j x, A=\sum_{k=m}^{\infty} \Delta a_{k} D_{k}(x)$ and $B=-a_{m} D_{m-1}(x)$.

Let $x$ in interval $(0, \pi]$, so we can find natural number $M$ satisfying $x \in\left(\frac{\pi}{M}, \frac{\pi}{M-1}\right]$. Because of

$$
\left|\sum_{v=1}^{m} \cos v x\right|=\left|\frac{\sin \left(m+\frac{1}{2}\right) x}{2 \sin \frac{1}{2} x}\right| \leq \frac{1}{2 \sin \frac{1}{2} x} \leq \frac{\pi}{2 x}
$$

we have

$$
|B|=\left|a_{m} D_{m-1}(x)\right| \leq \frac{\pi}{2 x}\left|a_{m}\right| \leq \frac{M}{2}\left|a_{m}\right|
$$

By (3.4) and $a_{i}$ nonnegative for each $i \in \mathbb{N}$, we obtain

$$
|A|=\left|\sum_{k=m}^{\infty} \Delta a_{k} D_{k}(x)\right| \leq \frac{\pi}{2 x}\left|\sum_{s=m}^{\infty} \Delta a_{s}\right| \leq \frac{M}{2}\left|\sum_{s=m}^{\infty} \Delta a_{s}+\sum_{s=m+1}^{\infty} \Delta a_{s}\right| \leq \frac{M}{2} \sum_{s=m}^{\infty}\left|a_{s}-a_{s+2}\right|
$$

By proof of Lemma 3.2 we have

$$
|A| \leq M C a_{m}
$$

Thus we get

$$
A+B \leq \frac{M}{2}\left(a_{m}+2 C a_{m}\right)
$$

For $x=0$ we have

$$
f(x)=\sum_{k=1}^{\infty} a_{k} \cos 0=\sum_{k=1}^{\infty} a_{k}<\infty
$$

finally by (3.2) and (3.5), we get

$$
\lim _{n \rightarrow \infty} f(x)-S_{m}(f, x)=0
$$

Then the series in point (3.1) converges uniformly on closed interval $[0, \pi]$. The proof is complete.

\section{Conclusion}

In this paper we have concluded that, necessary and sufficient condition of uniform convergence of cosine series with coefficient in new class of general monotone $G M\left(\mathbb{R}^{+}, 2\right)$ is $\lim _{n \rightarrow \infty} n b_{n}=0$. 


\section{Acknowledgements}

The author wants to say very thanks so much to the Department of Mathematics, FMIPA, University of Brawijaya that supports this article.

\section{REFERENCES}

[1] B. Szal, "A New Class of Numerical Sequences and its Applications to Uniform Convergence of Sine Series", arXive: 0905.1294v1[math.CA], May 8 ${ }^{\text {th }}, 2009$.

[2] M. A. Imron, "Application of Approximation Theory for Sine Series with Coefficient from Class Supremum Bounded Variation Sequences of First Type", AIP Conference Proceedings, vol. 1913 (020005), 2017.

[3] M. A. Imron, "The Error Calculation of Sine Series Approximation with Coefficient from Class of General Monotone Order r", AIP Conference Proceedings, vol. 2021 (060022), 2018.

[4] M. A. Imron, "Application New class of $p$-Supremum Bounded Variation Double Sequences", Journal of Engineering and Applied Sciences, vol. 13, no. 12, pp. 4279-4281, 2018.

[5] S. Tikhonov, "Best approximation and moduli of Smoothness computation and Equivalence Theorems", Journal of Approximation Theory, vol. 153, pp. 19-39, 2008.

[6] T. W. Chaundy and A. E. Jollife, "The Uniform Convergence of Certain Class Trigonometric Series", Proc. London, Soc. 15, pp. 214-116, 1916. 